\title{
STRATEGY FOR COST-EFFECTIVE ALLOY DESIGN OPTIMIZATION FOR STRENGTH AND DUCTILITY PROPERTIES OF STRUCTURAL STEELS
}

\author{
Jose Maria Rodriguez-lbabe ' \\ Houxin Wang ${ }^{2}$ \\ Douglas Glenn Stahlheim ${ }^{3}$ \\ Ronaldo Antonio Neves Marques Barbosa ${ }^{4}$
}

\begin{abstract}
Alloy, labor, and energy made up for major costs in the production of flat and long commodity-grade structural steel products. Flat and long commodity-grade structural steels such as ASTM A36, ASTM A527Gr50, S235, S275, S355, and other equivalent world societal standards represent over 500 million annual tons worldwide. Carbon, manganese, and silicon constitute the minimum base of alloying elements for the commodity structural steels. This base can be then supplemented with microalloying elements of either vanadium or niobium. Since 2016 raw material costs for two of the five alloying elements in these commodity-grade structural steels, $\mathrm{FeMn}$ and $\mathrm{FeV}$, have risen significantly and/or have become volatile. This is making difficult to maintain stability in profitability. For steel plants producing hundreds of thousands and in some cases over a million tons annually of these common structural steel grades, because of the significant alloy cost increase for $\mathrm{Mn}$ and $\mathrm{V}$, alloy additions have squeezed profitability. Commodity-grades usually represent the base loading for cost controls in most steel plants. Hence a significant cost increase or volatility in two of the five elements used for these grades will have a negative effect on overall production costs. However, with a proper strategy for alloy design working in conjunction with the mills' existing processing capabilities to achieve the desired end metallurgy/mechanical properties, alloy costs and operational efficiencies can be realized.
\end{abstract}

Keywords: Optimization; Strategy; Niobium; Microstructural modeling.

\section{INTRODUCTION}

Significant cost savings in the production of simple structural steel commodity grades can be realized if a proper understanding of the contribution to metallurgy and the final mechanical properties of the three basic elements of $\mathrm{C}, \mathrm{Mn}$ and $\mathrm{Si}$ and supplemental elements of $\mathrm{Nb}$ and $\mathrm{V}$ can result in. Alloy optimization can result in cost savings of US $\$ 2 /$ ton to US $\$ 20 /$ ton or in some cases higher. In a mill producing typically from 200,000 tons up to I million tons annually can represent cost-saving in an alloy of US $\$ 400,000$ up to US $\$ 20$ million annually [1]. Alloy optimization is something that cannot be ignored and must be explored because of the significant opportunity for cost savings. Many worldwide commodity flat and long products structural steel producers have already taken steps in alloy optimization of their production and have realized significant cost savings. An understanding of what creates strength and ductility for any given structural steel is what is needed to achieve these cost savings. Strength and ductility for any structural steel are obtained from three metallurgical mechanisms or "building blocks": a) grain size refinement; b) solid solution; and c) precipitation. If better engineering of these contributions can be realized for a given mill processing capabilities, alloy costs can be minimized resulting in significant annual cost savings. The correct use of these factors brings in addition process/mechanical property stability resulting in corresponding reductions in yield losses and additional operational cost savings. The use of practical metallurgical modeling tools along with mill data to determine process control capabilities can also assist in alloy/process designs or strategy for further cost optimization.

\section{ALLOY OPTIMIZATION STRATEGY}

With the recent increase and volatility of $\mathrm{Mn}$ and $\mathrm{V}$ in the past 3 years [2], it is imperative these days that an optimized cost-effective approach strategy to alloy design for strength and ductility be implemented.

'Materiales: Microalloyed steels, Centro de Estudios e Investigaciones Técnicas de Gipuzkoa, Donostia-San Sebastian, Spain.

${ }^{2}$ Research and development: microalloyed steels, Citic Group, Beijing, China.

${ }^{3}$ Research and Development: Microalloyed steels, DGS Metallurgical Solutions, Vancouver, WA, USA.

${ }^{4}$ Departamento de Engenharia de Metalúrgica e de Materiais, Universidade Federal de Minas Gerais - UFMG, Belo Horizonte, MG, Brasil.

E-mail: ranmbarbosa@gmail.com

2176-I523 (C) 2020. Rodriguez-lbabe et al. Published by ABM. This is an Open Access article distributed under the terms of the Creative Commons Attribution License, which permits unrestricted use, distribution, and reproduction in any medium, provided the original work is properly cited. 
It is important these days that an optimum cost-effective alloy design is implemented. International prices of FeMn increased to, approximately I.4 US\$/ton, from Dec, 16 to Oct, 19, from 0.7 US\$/ton since Dec, I5. FeV, around less than 20 US\$/ton on Dec, 15 raised to 40 US\$/ton on Dec, 17 , then kept increasing up to I 20 US\$/ton by Nov, I 8 and then went back to 40 US\$/ton by Oct, I9; a very volatile behavior.

Mechanical properties of any structural steel, ie, strength, ductility, toughness, elongation, formability, fatigue, flatness/shape are predominately driven by the average grain size (strength) and cross-sectional homogeneity of the grain size (ductility - toughness, elongation) [3]. Strengthening component of average grain size contributes to $40-70 \%$ of the strength, while average grain size/ homogeneity/heterogeneity/distribution through the cross-section represents two very significant contributing factors to ductility properties. Contributing components to strength and ductility can be seen in Figure I [4-6].

In many of the commodity-grade structural steels, strength is the main requirement with minimal ductility/toughness requirements. To achieve this, an updated alloy design strategy that is geared to alloy optimization for strength and ductility/toughness is necessary. Figure 2 shows the difference between the older outdated strategy vs. a newer cost- effective strategy.

As illustrated in Figure 2, since $40-70 \%$ of the strength and ALL the ductility properties come from the average grain size/distribution for a given microstructure, it only makes common sense to start the alloy design strategy for the process around this point. Once this "Step I" is completed, solid solution strengthening additions and post rolling precipitation strengthening mechanisms, Step 2 and Step 3, typically Mn for solid solution strengthening and $\mathrm{V}$ for post rolling precipitation in commodity-grade structure steel, should be done with a recognition of the current cost of these two alloys.

Post rolling precipitation strengthening mechanisms require a significant volume of fine precipitates to generate the strength as described in the Ashby-Orowan equation (Equation I) [7] where " $f$ " equals volume fraction of precipitate and " $x$ bar" equals the average diameter of the precipitates.

$$
\Delta \sigma_{\mathrm{ppt}}=\frac{5.9 \sqrt{\mathrm{f}}}{\overline{\mathrm{x}}} \ln \left(\frac{\overline{\mathrm{x}}}{2.5 \times 10^{-4}}\right)
$$

Metallurgy requires, regardless of the microalloying element $(\mathrm{V}, \mathrm{Nb}, \mathrm{Ti})$ to have a significant volume of microalloy
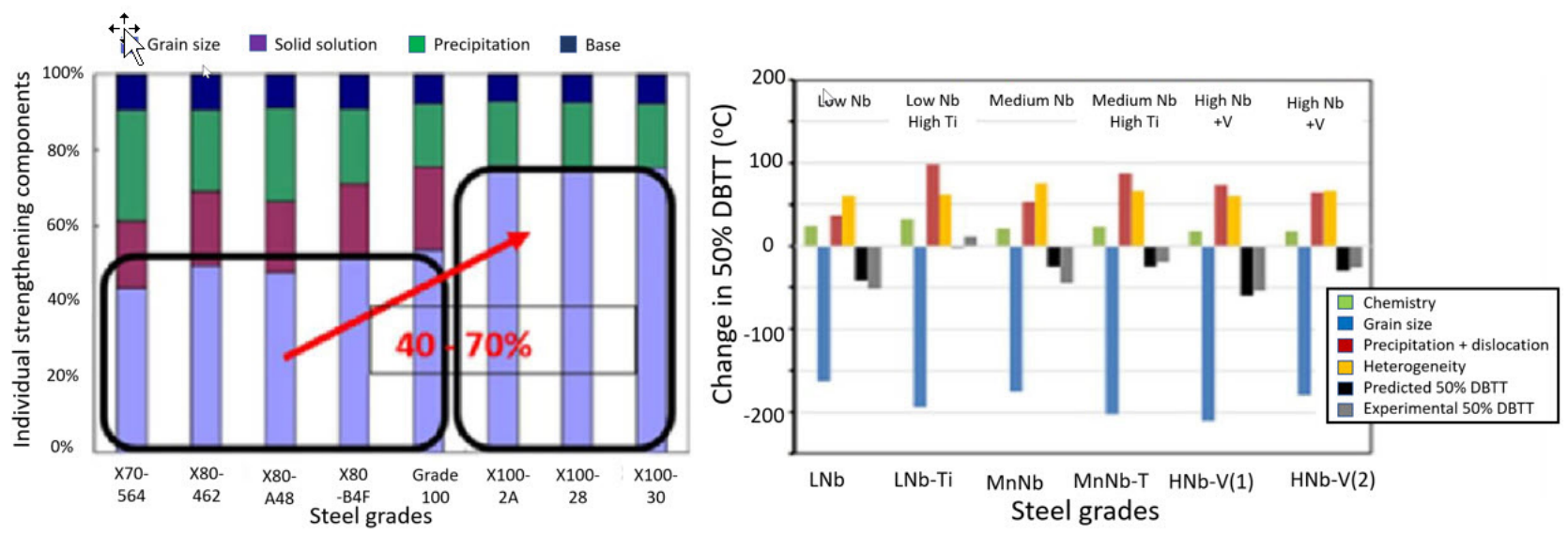

Figure I. Strength and ductility components illustrated.
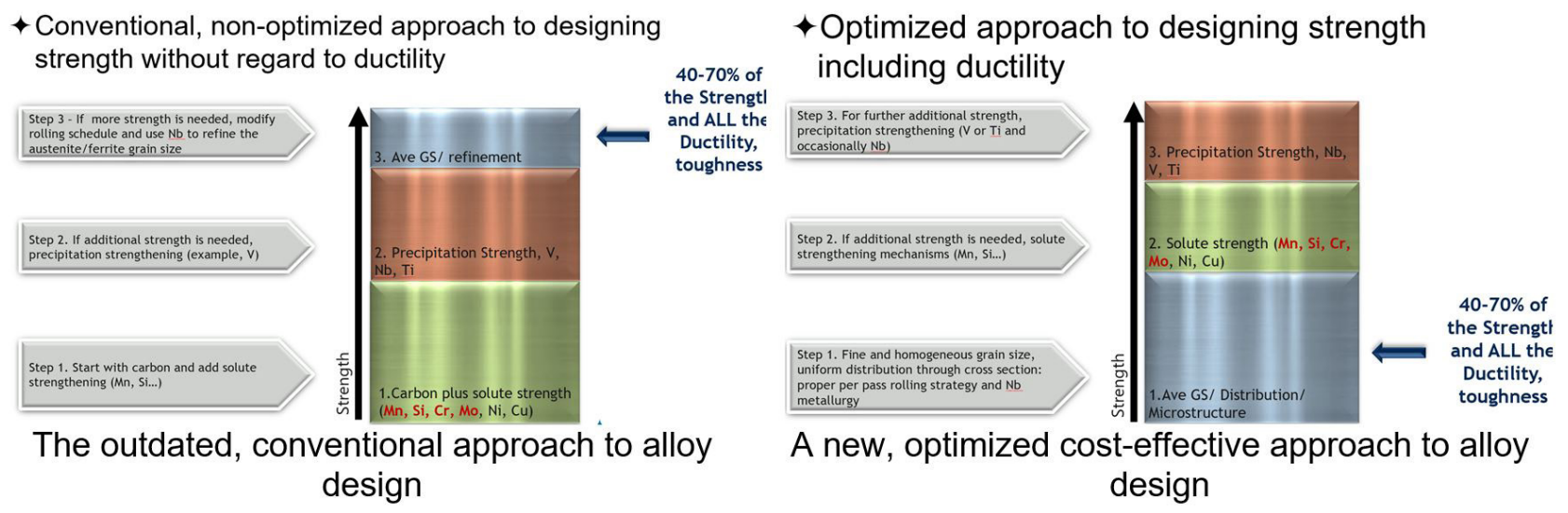

Figure 2. Illustration of outdated conventional vs. new optimized cost-effective approach to alloy design for strength and ductility. 
still in solution upon entry to the post rolling cooling phase that could potentially precipitate. How much microalloy is still in solution being dependent on prior processing parameters in some cases such as Ti going all the way back to the LMF process in steelmaking is typically an unknown. Then the post rolling cooling rate must be controlled precisely for interphase precipitation to occur or the post rolling final cooling must be in the correct temperature range for random precipitation to be effective $[8,9]$. Very few steel producers control the post rolling cooling in a way that would promote effective/optimum use of post rolling precipitation and hence results in variable stability of final mechanical properties, Figure 3, "wasting" costly alloy additions. Most steel producers just add some significant volume of the microalloy, typically from $0.030-0.100 \%$, hoping that some amount of precipitation strengthening will occur within their natural post rolling cooling process. This is not an efficient or cost-effective approach to commodity structural steel production these days.

\section{COST-EFFECTIVE APPROACH}

It has been well established that during hot rolling, controlling the austenite grain size and recrystallization behavior can contribute to a major, effect in developing that first metallurgical building block, i.e. Step I [10]. By utilizing even dilute amounts of $\mathrm{Nb}$ microalloying during hot rolling austenite grain size can be positively modified. This modification can allow for a reduction in solid solution strengthening or post rolling precipitation strengthening mechanisms, primarily $\mathrm{Mn}$ and $\mathrm{V}$, resulting in alloy cost savings and stable mechanical properties. For instance, consider the effect $\mathrm{Mn}$ the solution strengthening contribution to strength utilizing equations for YS and TS developed by Pickering, see Equation (2) below [I I]. From these equations, the contribution of $\mathrm{Mn}$ to both $\mathrm{YS}$ and TS can be calculated, Table I.

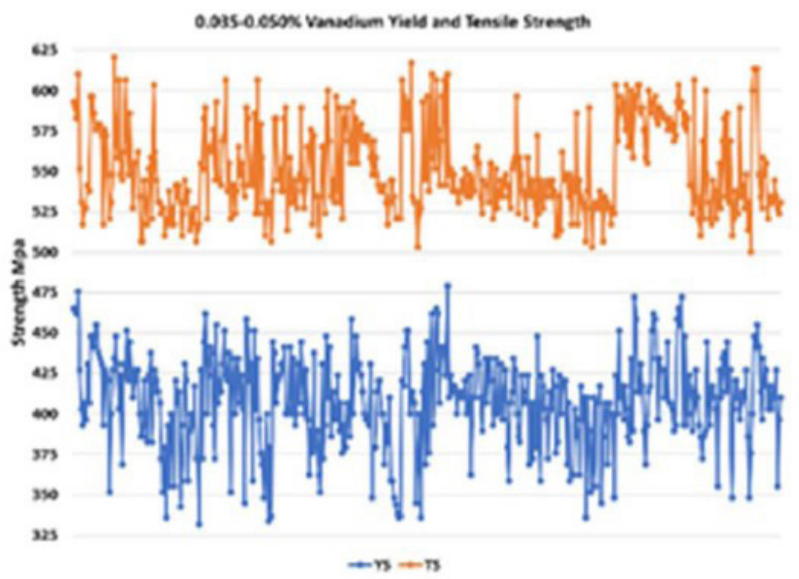

$$
\begin{aligned}
& \mathrm{YS}=53.9+32.3 \mathrm{Mn}+83.2 \mathrm{Si}+354.2 \sqrt{\mathrm{N}_{\mathrm{sol}}}+\frac{17.4}{\sqrt{\mathrm{d}}} \\
& \mathrm{TS}=294.1+27.7 \mathrm{Mn}+83.2 \mathrm{Si}+2.85 \text { Pearl }+\frac{7.7}{\sqrt{\mathrm{d}}}
\end{aligned}
$$

Table I shows that reducing the Mn content of 0.30 or $0.50 \mathrm{Mn}$ only there is a contribution of $10-16 \mathrm{MPa}$ of YS and 8-14 MPa of TS. So, if Mn costs can be optimized by reducing $\mathrm{Mn}$ by 0.30 or $0.50 \%$, then the replacement of YS and TS needs to come from another strengthening component. Within the Pickering strength equation is also grain size "d". If the average final ferrite grain size can be changed by only $2 \mu \mathrm{m}, 16 \mathrm{MPa}$ of YS and $8 \mathrm{MPa}$ of TS can be realized as calculated in the Pickering equation. This means that up to $0.50 \% \mathrm{Mn}$ could be reduced successfully with a minor change in the final ferrite grain size, hence improving alloy costs.

Recent research by Zhe [12] has shown that dilute amounts of $\mathrm{Nb}$, even at rolling temperatures $>950^{\circ} \mathrm{C}$ can refine the austenite grain size, Figure 4 . The Figure shows that at $1000^{\circ} \mathrm{C}$ a dilute $\mathrm{Nb}$ addition of $0.010 \%$ can reduce the austenite grain size from $80 \mu \mathrm{m}$ to $60 \mu \mathrm{m}$ resulting in a potential $2 \mu \mathrm{m}(16 \mu \mathrm{m}$ to $14 \mu \mathrm{m})$ final ferrite grain size reduction.

Using current published $\mathrm{HiC}$ FeMn pricing for Europe and average $\mathrm{FeNb}$ pricing at the end of May 2019, a reduction of $0.30-0.50 \% \mathrm{Mn}$ with a dilute addition of $0.010 \% \mathrm{Nb}$ can result in a cost savings of USD $\$ 1.31-4.59 /$ ton. Most structural mills will produce between 250,000-500,000 annual tons of lower strength S235, S275 and S355 or equivalent grades which means if $\mathrm{Mn}$ can be reduced in these grades with a dilute $\mathrm{Nb}$ addition of $0.010 \%$, annual cost saving ranging

Table I. Contribution of $\mathrm{Mn}$ to $\mathrm{YS}$ and TS

\begin{tabular}{ccc}
\hline$\% \mathbf{M n}$ & Contribution to YS & Contribution to TS \\
\hline $\mathbf{0 . 3 0}$ & $10 \mathrm{MPa}$ & $8 \mathrm{MPa}$ \\
$\mathbf{0 . 5 0}$ & $16 \mathrm{MPa}$ & $14 \mathrm{MPa}$ \\
$\mathbf{1 . 0 0}$ & $32 \mathrm{MPa}$ & $28 \mathrm{MPa}$ \\
\hline
\end{tabular}

YS and TS here mean yield and tensile stresses respectively.

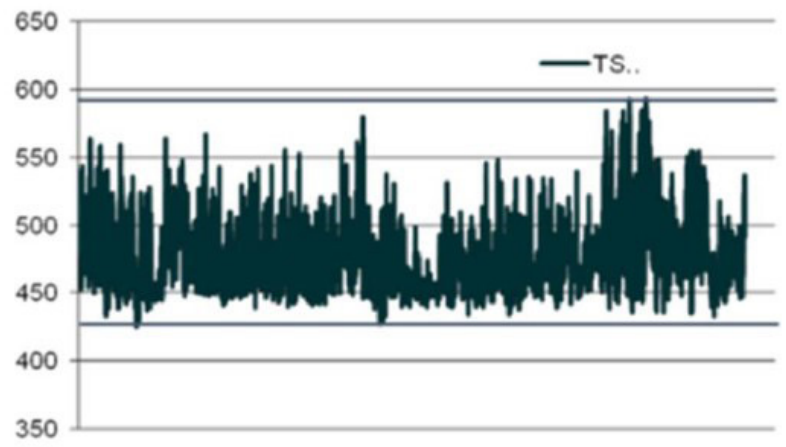

Figure 3. Examples of YS and TS of $\mathrm{V}$ and Ti post rolling production precipitation strengthening stability due to lack of post rolling cooling process control. 
from USD $\$ 327,500 / \$ 655,000$ - $\$ 1.15-2.30$ million annually could be realized. This does not include any significant cost savings that can be realized from productivity enhancements, inventory minimization or improved yield performance from an optimized alloy design.

A similar approach can be used to realize a reduction or complete removal of $\mathrm{V}$ with minor amounts of $\mathrm{Nb}$ or even a combination of $\mathrm{V} / \mathrm{Nb}$ with reduced Mn, Figure 5 [13].

Alloy optimization can be accomplished by using actual production chemistry, basic processing (reheat/FRT) and resulting mechanical properties to calibrate empirically designed physical prediction models to simulate possible options as was illustrated in Figure 5. The goal is not to change anything in the existing process parameters of the production, but to design and optimized alloy to fit the existing production process parameters. This type of modeled simulation using actual mill data can allow for a more robust approach to a possible cost-effective optimized alloy design that can be used for the trial. Once the trial is completed, fine-tuning of the alloy can be done as required and if desired minor optimization of the processing can be implemented using available tools such as MicroSim ${ }^{\circledR}$ austenite evolution modeling.
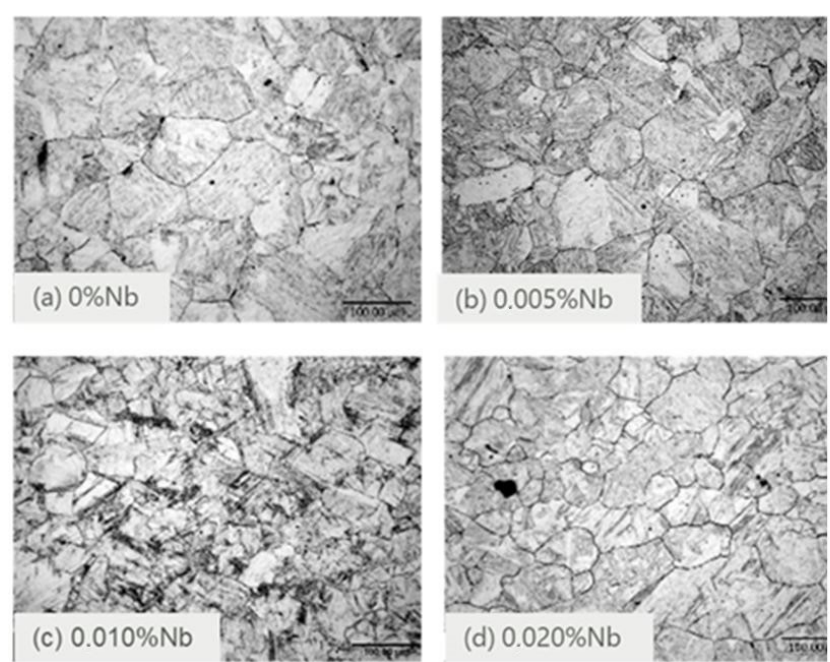

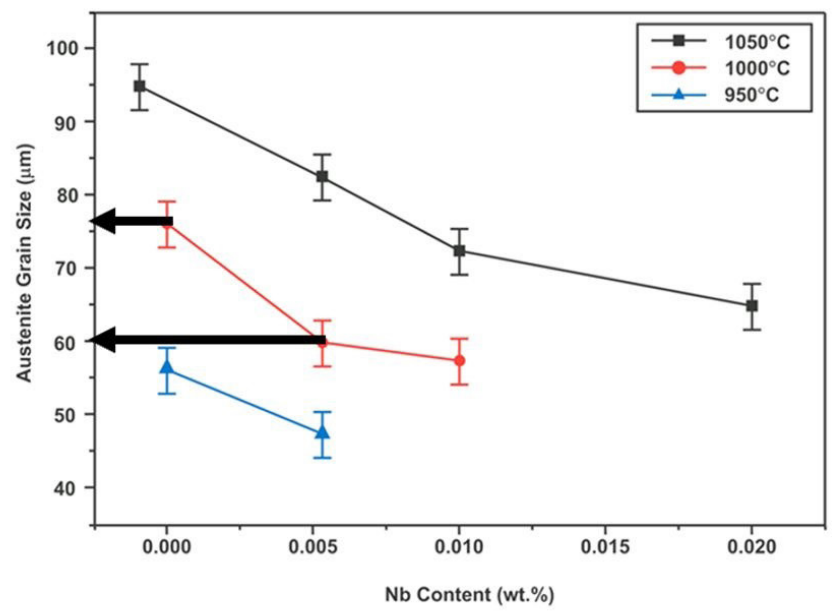

Figure 4. Austenite grain size evolution of $0.08 \% \mathrm{C}$ steel after 20 second holding period at $1000^{\circ} \mathrm{C}$ followed by water quenching vs. $\mathrm{Nb}$ level.

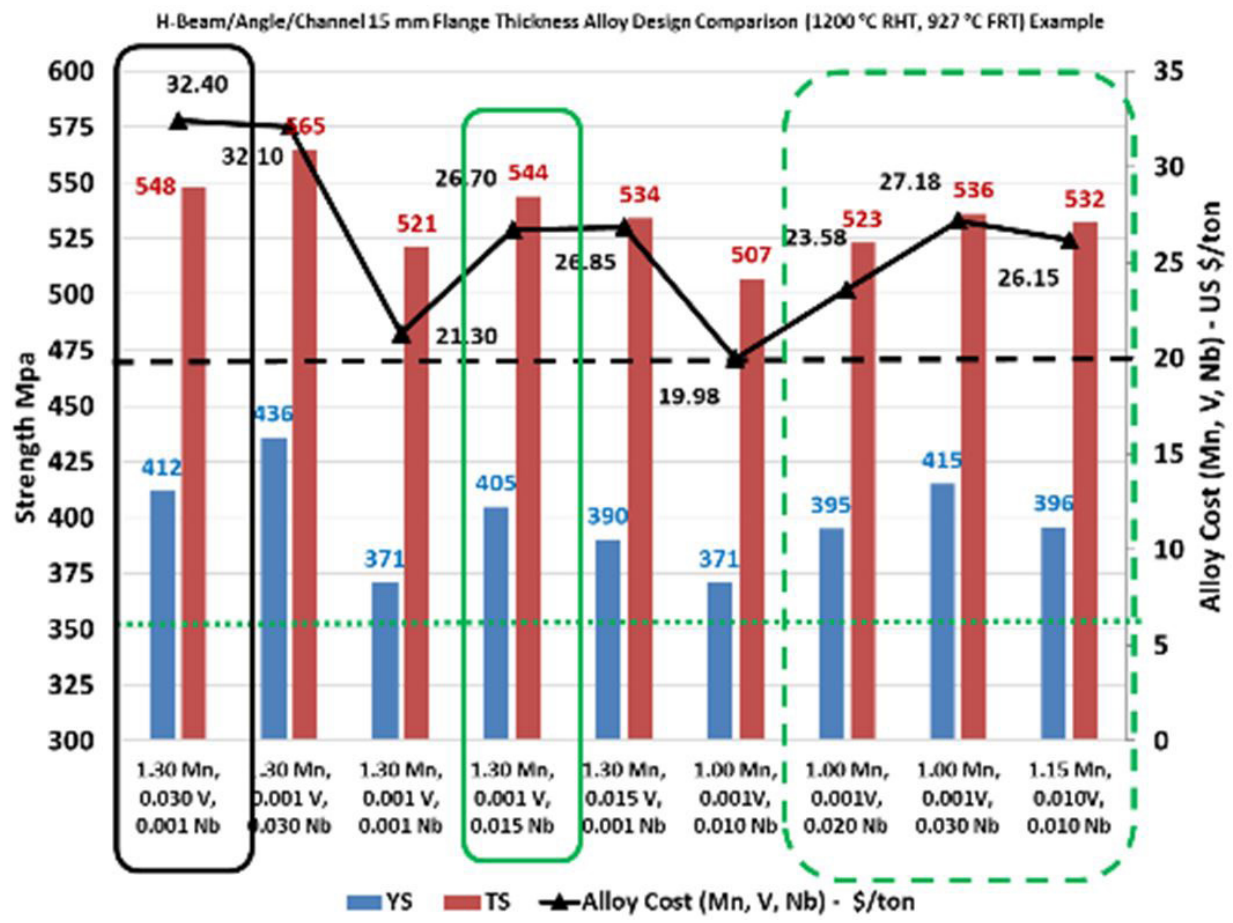

Figure 5. Example of alloy optimization modeled simulated strength possibilities for $15 \mathrm{H}$-beam considering $\mathrm{Mn}, \mathrm{V}$, and $\mathrm{Nb}$. YS and TS here mean yield and tensile stresses respectively. 


\section{RESULTS AND EXAMPLES}

Figure 6 shows examples of strengthening by two different mechanisms: post rolling precipitation and grain refinement. Affecting austenite grain size and hence final ferrite grain size is much easier to implement consistently as a strengthening mechanism than that of post rolling precipitation strengthening.

Figure 7 shows examples of results obtained from a $0.50 \% \mathrm{Mn}$ reduction with a dilute $0.010 \% \mathrm{Nb}$ addition on mechanical properties and flatness at NISCO.

Minor changes in final ferrite grain size, as little as a $2 \mu \mathrm{m}$, is enough to allow for a $0.50 \% \mathrm{Mn}$ reduction and still produce the same strength level. This concept was successfully implemented at Nanjing Iron and Steel (NISCO) in 2017 in structural steel $345 \mathrm{MPa}$ minimum YS up to $40 \mathrm{~mm}$ in thickness. Strength and flatness requirements have been easily achieved in mass production. In addition, one single slab chemistry design has been successfully used to feed three different plate mills, standardized rolling strategies among the three plate mills and produce several different plate grades/versions of $345 / 355$ minimum yield strength products.

Figure 8 shows a comparison of microstructure and grain size for a $20 \mathrm{~mm}$ plate comparison of higher $\mathrm{Mn}$ no Nb and lower $\mathrm{Mn}$ with $0.010 \% \mathrm{Nb}$ structural steel. Analysis of various strengthening components is also presented. Note the average ferrite grain size difference at the $1 / 4$ and center thicknesses close to a $2 \mu \mathrm{m}$ difference.

Figure 9 shows that there is an obvious improvement in slab centerline alloy segregation quality and corresponding microstructural banding.

MicroSim ${ }^{\circledR}$ PM modeling of the austenite grain size evolution of the $\mathrm{C} / \mathrm{Higher} \mathrm{Mn}$ alloy design vs. the $\mathrm{C} /$ Lower $\mathrm{Mn} 0.010 \% \mathrm{Nb}$ design also shows the same trends in the
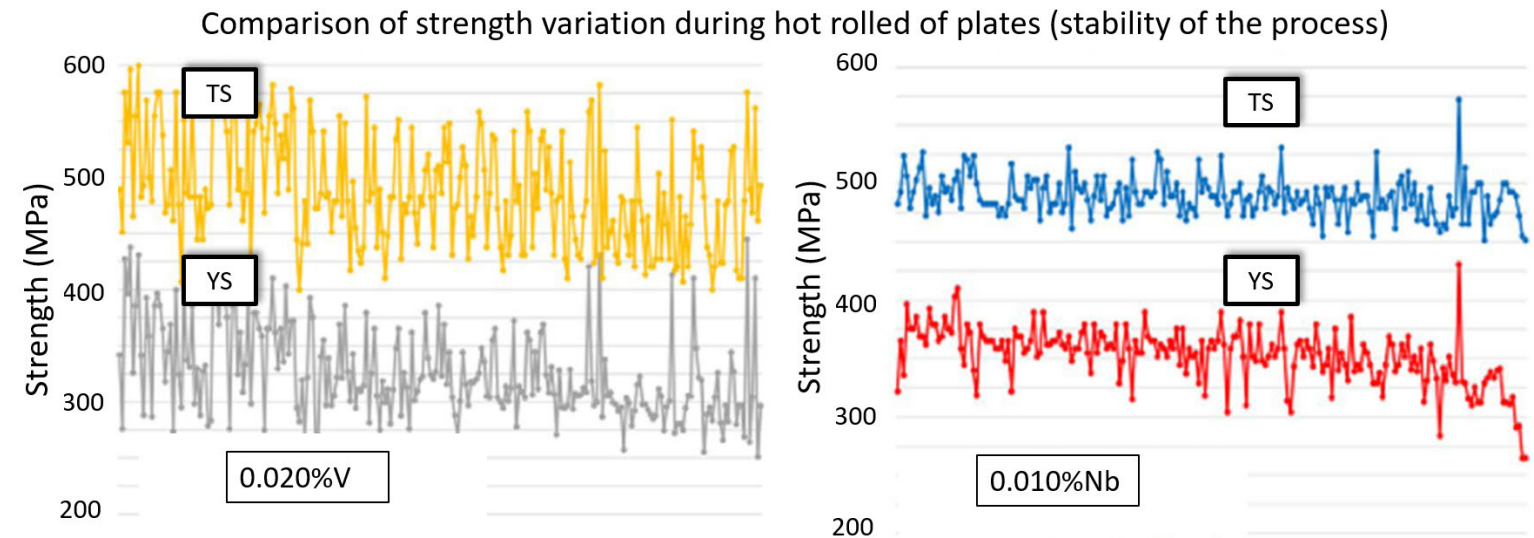

Figure 6. ASTM A572 Gr50 post rolling precipitation strengthening vs. austenite/ferrite grain size refinement strengthening comparison of $V$ and $\mathrm{Nb}$ in hot rolled structural steel plate production. YS and TS here mean yield and tensile stresses respectively. Each represent mechanical properties obtained from a rolled industry run.
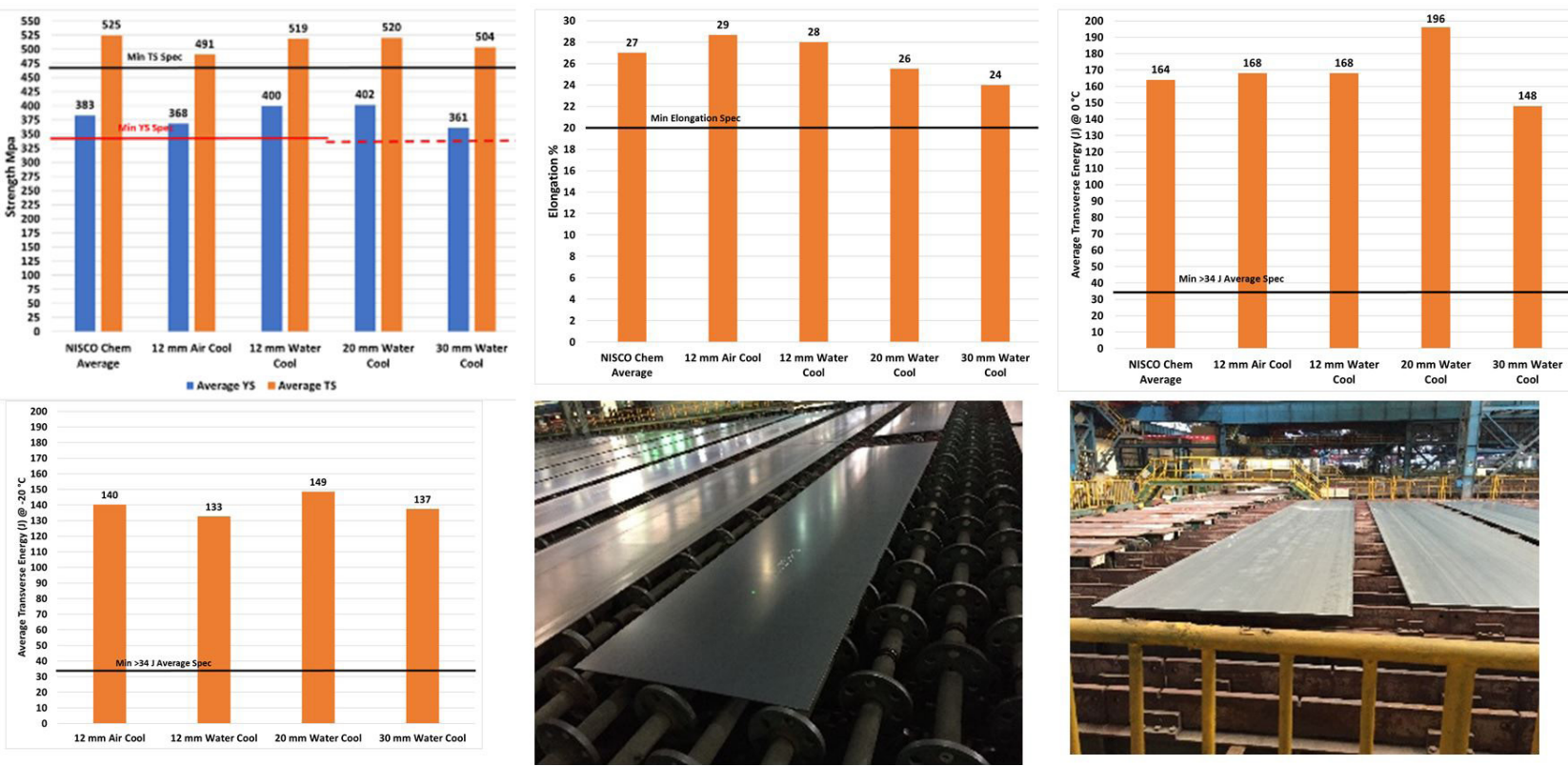

Figure 7. Examples of results obtained from a $0.50 \% \mathrm{Mn}$ reduction with a dilute $0.010 \% \mathrm{Nb}$ addition mechanical properties and flatness at $\mathrm{NISCO}$. 


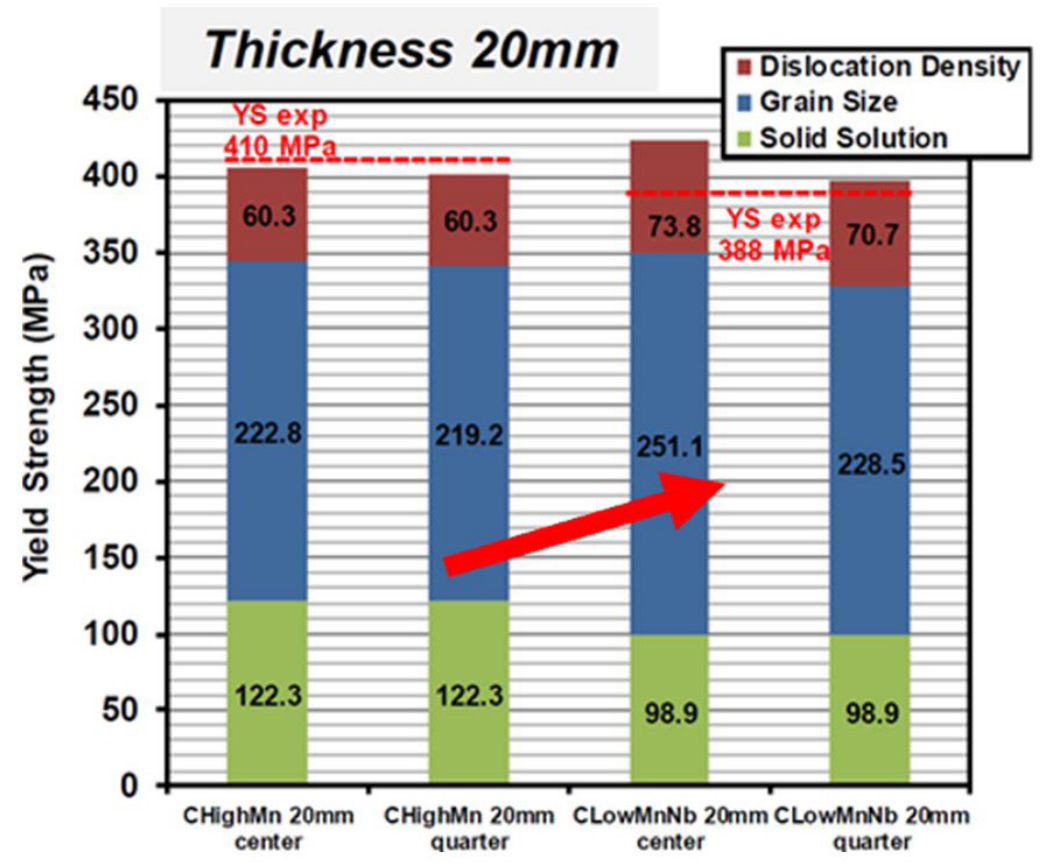

Figure 8. Comparison of microstructure and grain size for a $20 \mathrm{~mm}$ plate comparison of higher $\mathrm{Mn}$ no $\mathrm{Nb}$ and lower $\mathrm{Mn}$ with $0.0 \mathrm{I} 0 \% \mathrm{Nb}$ structural steel. YS and TS here mean yield and tensile stresses respectively.

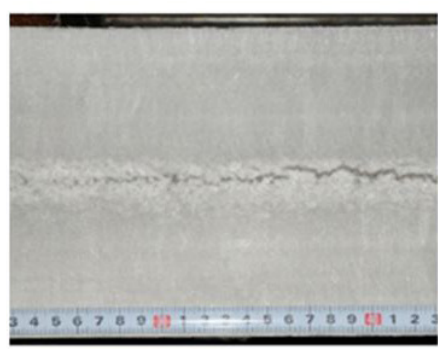

C- $0.16 \%, \mathrm{Mn}-1.30 \%$

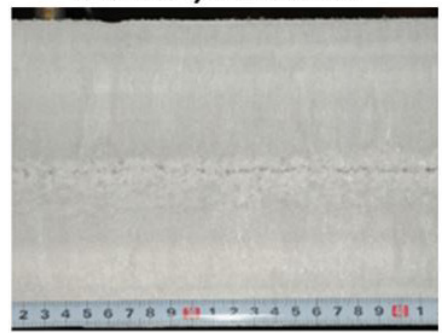

C- $0.16 \%, \mathrm{Mn}-1.05 \%$
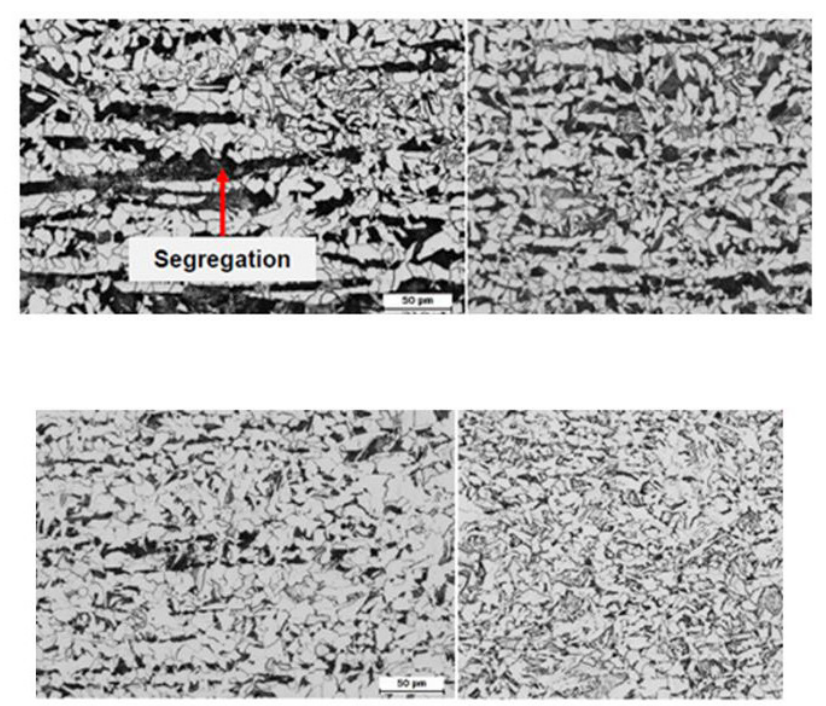

Figure 9. Slab macroetch and microstructural banding comparison between higher and lower Mn.

austenite evolution. Modeling indicates an overall finer austenite evolution and better cross-sectional distribution at the end of the rolling process, Table 2 . Figure 10 shows industry results in which addition of $\mathrm{Nb}$ replacing $\mathrm{V}$ improved mechanical properties in the case of $\mathrm{H}$ beams, and also decreased 2-sigma values, demonstrating better process control (case shown in rebars) [14].

Since the increase in FeMn costs starting in late 2016 and then FeV pricing increase/volatility starting in late 2017 there has been strong interest by many structural steel producers to optimize their alloy costs for $M n$ and $V$ additions. This has been done in plates, hot strip, $\mathrm{H}$-beams, angles and rebar around the world. In some cases, there is already a purposeful $\mathrm{Nb}$ addition, such as $0.010 \%$ that can be increased by $0.010 \% \mathrm{Nb}$ to $0.020 \% \mathrm{Nb}$ and then the Mn reduced by $0.30 \%$ or more allowing for USD \$I-2/ton of cost savings depending on $\mathrm{Mn}$ and $\mathrm{Nb}$ pricing. Additional examples of grades and products that have been optimized for $\mathrm{Mn}$ and $\mathrm{V}$ utilizing $\mathrm{Nb}$ are as follows:

a) Hot Strip-S355 up to $16 \mathrm{~mm}, \mathrm{Mn}$ reduction with $0.010 \%$ $\mathrm{Nb}, \mathrm{Mn}$ reduction $\mathrm{V}$ removed with $0.025 \% \mathrm{Nb}$; 
Table 2. MicroSim ${ }^{\circledR}$ austenite evolution modeling output comparison of austenite grains between $\mathrm{C} / \mathrm{Mn}$ vs. C/Mn/Nb $20 \mathrm{~mm}$ plate steel

\begin{tabular}{|c|c|c|c|}
\hline & Average Austenite GS $\mu \mathrm{m}$ & $\begin{array}{c}\text { 90\% Max Austenite GS } \mu \mathrm{m} \\
(\text { (Dc 0.10) }\end{array}$ & Maximum Austenite GS $\mu \mathrm{m}$ \\
\hline $0.16 \% \mathrm{C} / 1.40 \% \mathrm{Mn}$ & 23 & 73 & 254 \\
\hline $0.16 \% \mathrm{C} / 0.90 \% \mathrm{Mn} / 0.010 \% \mathrm{Nb}$ & 18 & 50 & 192 \\
\hline
\end{tabular}

GS means Grain Size and YS and TS are the yield and tensile stresses respectively. Dc 0.10 is the grain size value below which $90 \%$ of all grains in the sample are found.'
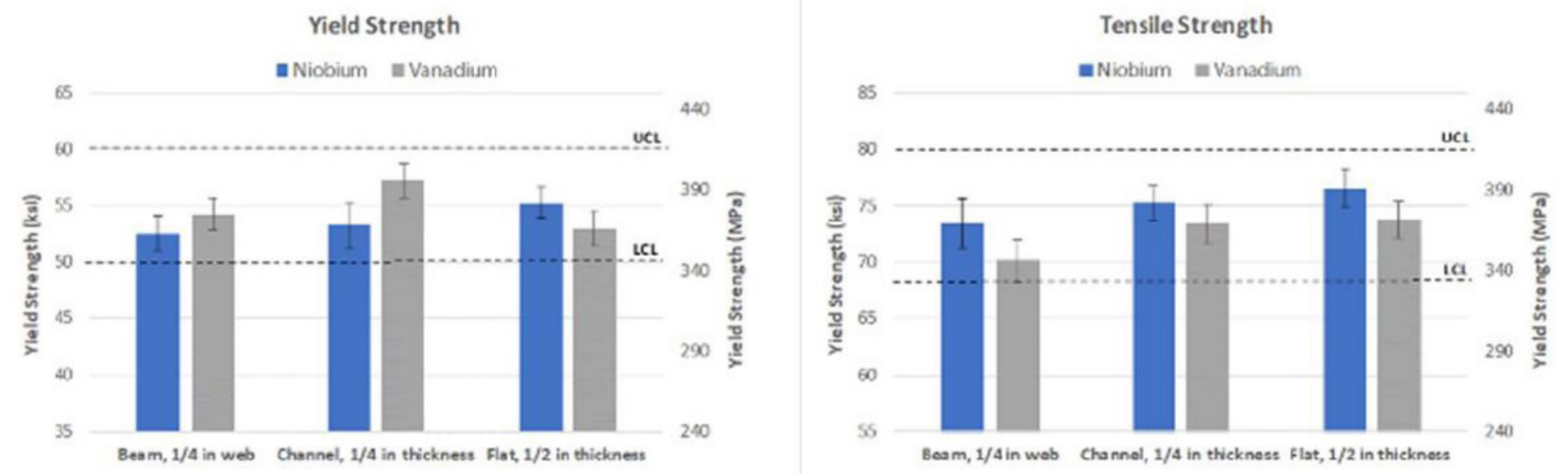

Figure 10. $\mathrm{H}$-beams, angles and rebar examples of $\mathrm{Nb}$ alloy optimization of $\mathrm{V}$. Note the improvement in 2-sigma control with $\mathrm{Nb}$ which is typical of all products seen to date when using $\mathrm{Nb}$ in alloy optimization. YS here means the yield stress of the steel.

b) Plate - S355, AH32/AH36, AH/DH36, SM490;

c) H-beams/Angles - S355, A572 Gr50;

d) Rebar - $400 \mathrm{MPa}$ min YS.

\section{CONCLUSIONS}

Two of the five main elements used in the production of commodity-grade structural steels have increased and/or have become volatile over the past 2 years applying profit pressure on many steel producers around the world who rely on these commodity grades to cover their base production costs. It has been demonstrated that with a proper understanding of the three main building blocks for metallurgy/mechanical properties and how to use each element properly via alloy optimization, production costs can be improved. Tools such as calibrated empirical physical prediction models and MicroSim ${ }^{\circledR}$ austenite evolution modeling can be used to properly optimize the alloy design and process parameters for the overall optimization of production costs of structural steels.

\section{REFERENCES}

I Barbosa R, Ibabe JM, Stalheim D, Rebellato M. Alloy cost optimization through proper metallurgical development of strength and ductility properties in structural steels. In: AISTech 20 I8: Proceedings of the Iron \& Steel Technology Conference; 2018 May 7-10; Philadelphia, PA, USA. Warrendale: Association for Iron \& Steel Technology; 2018.

2 Argus Metals. Metals bulletin. London: CBMM.

3 Stalheim D. Generation of stable optimized thru-thickness mechanical properties in wide heavy gauge structural steel plate. In: AISTech 2018: Proceedings of the Iron \& Steel Technology Conference; 2018 May 7-10; Philadelphia, PA, USA. Warrendale: Association for Iron \& Steel Technology; 2018.

4 Lu J, Ivey D, Henein H, Wiskel J, Omotoso O. Microstructure characterization and strengthening mechanisms of microalloyed steels. In: Proceedings of 2008 ASME International Pipeline Conference; 2008; Sept; Calgary, Canada. New York: American Society of Mechanical Engineers; 2008.

5 Isasti N, Jorge-Badiola D, Taheri ML, Uranga P. Microstructural features controlling mechanical properties in Nb-Mo microalloyed steels part II: impact toughness. Metallurgical and Materials Transactions A, Physical Metallurgy and Materials Science. 20I4;45(I I):4972-4982.

6 Ibabe JM, Uranga P, Isasti N, Stalheim D, Kendrick V, Frye B, et al. Optimized cost-effective production of structural hot rolled CSP coils through proper austenite conditioning. In: Proceedings of AISTech 2017; 2017; Pittsburgh, PA, USA. Warrendale: Association for Iron \& Steel Technology; 2017. 
7 Pickering FB. Some aspects of the relationships between the mechanical properties of steels and their microstructures. Tisco. 1980;27(I): 105-132.

8 Zajac S. Precipitation of microalloy carbo-nitrides prior, during and after $\gamma / \alpha$ transformation. Materials Science Forum. 2005;500-501:75-86. http://dx.doi.org/I0.4028/www.scientific.net/MSF.500-50I.75.

9 Chen C-Y, Yang J-R, Chen C-C, Chen S-F. Microstructural characterization and strengthening behavior of nanometer sized carbides in Ti-Mo microalloyed steels during continuous cooling process. Materials Characterization. 2016;114:18-29.

10 Barbosa R, Uranga P, Rodriguez-lbabe JM, Stahlheim D, Rebellato M, Qiao ML, et al. Microalloying additions to commodity C-Mn structural steels: fundamental strengthening mechanisms leading to improvements in mechanical properties, alloy optimization, reduced alloy costs and robustness of hot rolling processing. In: THERMEC 20।8: Proceedings of the 10th International Conference on Processing and Manufacturing of Advanced Materials; 20I8; Paris, France. Zurich: Trans Tech Publications; 2018.

II Pickering FB. Physical metallurgy and the design of steel. London: Allied Science Publishers; 1978. 275 p.

12 Zhe C. Thermomechanical processing of structural steels with dilute niobium additions [thesis]. Sheffield: University of Sheffield; 2016.

13 Siwecki T, Sandberg A, Roberts W, Lagneborg R. The influence of processing route and nitrogen content on microstructure development and precipitation hardening in vanadium microalloyed HSLA-steels. In: Proceedings of Thermomechanical Processing of Microalloyed Austenite; 1982; Pittsburgh, PA. Warrendale: AIME; 1982. p. 163-194.

14 Mesquita R, Wang Y, Williams B, Heerema J, Jansto S, Yalamanchili B. A case study on niobium substituting vanadium in long products. In: Proceedings of MS\&T 2018; 20I8; Columbus, OH, USA. Westerville: American Ceramic Society; 2018.

Received: 2 I Feb. 2020

Accepted: 22 Apr. 2020 